\title{
Electrodeposition Combination with Hydrothermal Preparation of ZnO Films and Their Application in Dye-Sensitized Solar Cell
}

\author{
Xiaoping Zou, Yan Liu, Cuiliu Wei, Zongbo Huang, and Xiangmin Meng \\ Research Center for Sensor Technology, Beijing Key Laboratory for Sensor, Ministry-of-Education Key Laboratory for \\ Modern Measurement and Control Technology, School of Sciences, Beijing Information Science and Technology University, \\ Jianxiangqiao Campus, Beijing 100101, China \\ Correspondence should be addressed to Xiaoping Zou; xpzou2005@gmail.com
}

Received 19 February 2014; Revised 6 May 2014; Accepted 20 May 2014; Published 30 June 2014

Academic Editor: Md. Abu Bin Hasan Susan

Copyright (C) 2014 Xiaoping Zou et al. This is an open access article distributed under the Creative Commons Attribution License, which permits unrestricted use, distribution, and reproduction in any medium, provided the original work is properly cited.

\begin{abstract}
A suitable method is necessary for the high performance of dyes-sensitized solar cells (DSSCs). In this paper, photoanodes of DSSCs have been fabricated through electrodeposition and combination with hydrothermal method. The results of mix method showed better performance than the single one. After the second step electrodeposition, the ZnO films formed flack finally. With the increase of hydrothermal time, $\mathrm{ZnO}$ films become thicker and bigger, which can offer large surface area to absorb much more dyes. The short-circuit current $\left(2.4 \mathrm{~mA} / \mathrm{cm}^{2}\right)$ and open-circuit voltage $(0.67 \mathrm{~V})$ were greater than the single one, alternating current impedance indicating that electrodeposition and hydrothermal mix are a more suitable method for high performance DSSCs. We expected to obtain higher conversion efficiency of DSSCs by this method.
\end{abstract}

\section{Introduction}

As a promising solar-to-electric energy converter, DSSCs have attracted much attention due to their high efficiency and low cost [1-3]. With regard to photovoltaic devices, the conventional silicon-based solar cells are usually too bulky and heavy for flexible applications. Fortunately, new generation photovoltaic devices, such as dye-sensitized solar cells (DSSCs) and organic solar cells [4-6], make it possible to utilize solar energy more efficiently. As a result, invented new methods have recently attracted much attention to mesoporous film in the photoanodes of dye-sensitized solar cells (DSSCs) and quantum dots-sensitized solar cells (QDSCs). However, insufficient internal surface area limits conversion efficiency at a relatively low level owing to deficient dyes loading and light harvesting [3].

$\mathrm{ZnO}$ is one of the most important semiconductor materials as the photoanodes of DSSCs and QDSCs due to its suitable energy-band structure and excellent physical properties. $\mathrm{ZnO}$ has a potential in the applications ranging from catalysis and sensors to dye-sensitized solar cells (DSSCs) and quantum dots-sensitized solar cells (QDSCs) [7-12]. Up to now, to get high performance, many methods have been explored to prepare $\mathrm{ZnO}$ porous films to offer large specific surface area for high device performance, such as doctor-blade (DB) method, chemical bath deposition, and electrodeposition (ED). In this paper, we expected to fabricate high performance photoanodes for dyes-sensitized solar cells (DSSCs). TiCl4 pretreatment was used on FTO before fabricating $\mathrm{ZnO}$ films by electrochemical method. The morphology of $\mathrm{ZnO}$ films was changed after $\mathrm{TiCl} 4$ pretreatment, which can offer large surface area to absorb much more dyes. We try to differentiate electrodeposition time. When the time of electrodeposition was $3 \mathrm{~min}$, the quantum dyes-sensitized solar cells (DSSCs) based on TiCl4 pretreatment $\mathrm{ZnO}$ films showed more superior photoelectrochemical performance.

\section{Experimental}

2.1. Preparation of $\mathrm{ZnO}$ Photoanodes. The first step is hydrothermal method. Preparing the molar concentration of $0.005 \mathrm{M} \mathrm{Zn}\left(\mathrm{NO}_{3}\right)_{2}$ and hexamethylenetetramine solution, then ultrasonically processing for $10 \mathrm{~min}$ so it is completely dissolved and then mixed. Put the prepared FTO into the beaker, pour into the prepared reaction solution, and seal, 

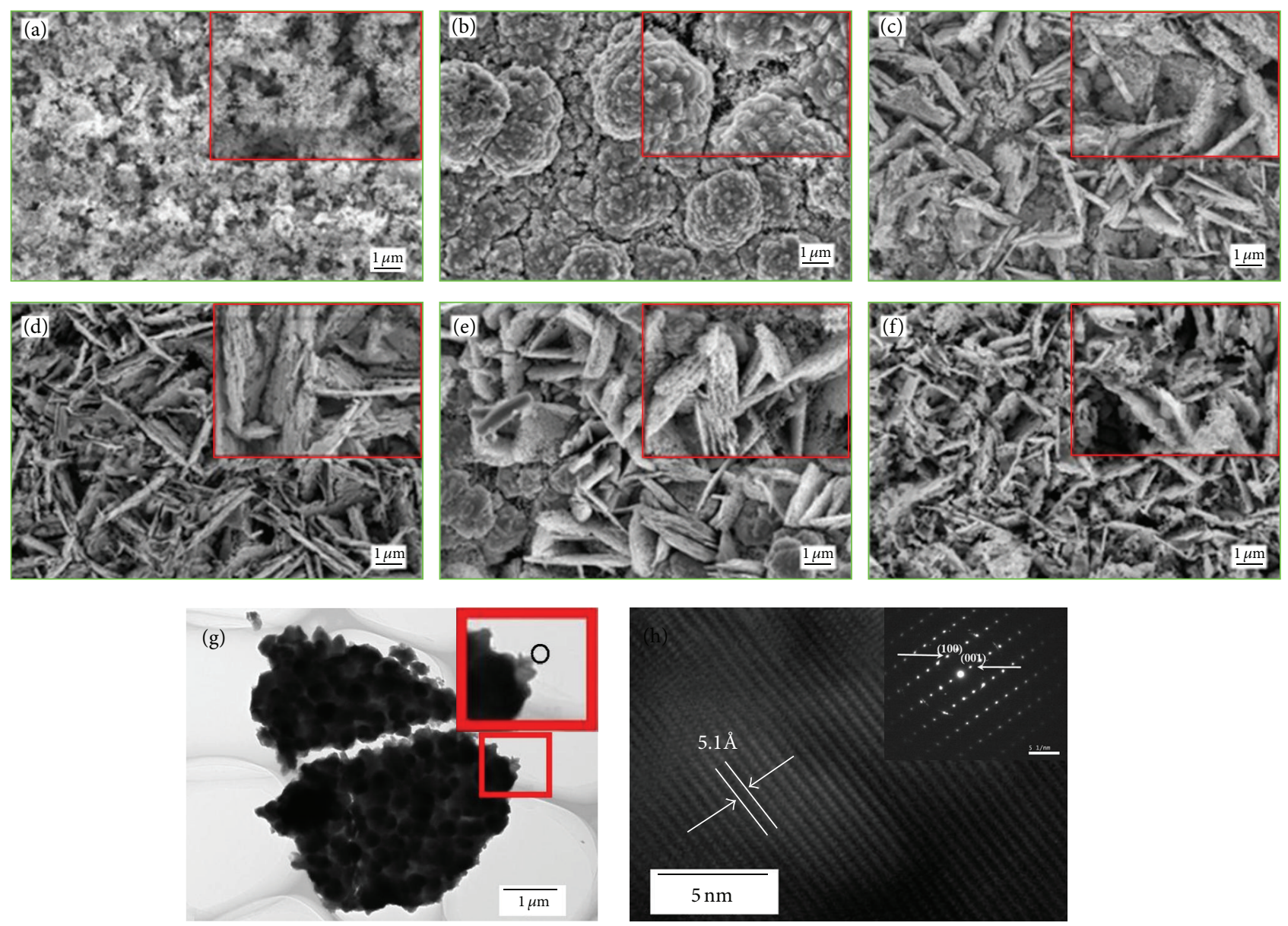

Figure 1: SEM images of the samples D2, E2, and F2, and G2, H2, and I1 after annealing, corresponds to (a), (b), (c), (d), (e), and (f), respectively. (g) Typical TEM and (h) HRTEM image of the sample, inset is the SAED of (g).

then put the beaker in the oven to maintain constant temperature at $95^{\circ} \mathrm{C}$; reaction time was $0.5 \mathrm{~h}, 1 \mathrm{~h}, 2 \mathrm{~h}, 3 \mathrm{~h}$, and $4 \mathrm{~h}$, respectively. After the reaction, remove and wash with deionized water, and then it is calcined at $450^{\circ} \mathrm{C}$ for $30 \mathrm{~min}$, the samples D1, E1, F1, G1, and $\mathrm{H} 1$ were obtained, respectively.

The second step is electrochemical method. Electrodeposition time is $8 \mathrm{~min}$, while electrodeposition current is $10 \mathrm{~mA}$. When the reaction stopped, remove and wash with deionized water, dry reserve, obtaining the samples D2, E2, F2, G2, and $\mathrm{H} 2$, respectively. Intended as a comparison, only carry out the second step electrochemical preparation of $\mathrm{ZnO}$ films as sample I1.

The above prepared samples F1, D2, E2, F2, G2, and H2 were calcined at $450^{\circ} \mathrm{C}$ for $30 \mathrm{~min}$, to be naturally cooled to $80^{\circ} \mathrm{C}$ and removed. Then they were immersed in the prepared N719 dye for $12 \mathrm{~h}$ and removed out, consequently washed with ethanol and air dried. Finally $\mathrm{ZnO}$ photoanode samples $\mathrm{Fl}^{\prime}$, D3, E3, F3, G3, H3, and I2 were obtained.

2.2. Characterizations. In order to be able to observe the characterization of $\mathrm{ZnO}$ films, we used scanning electron microscope (SEM) to observe and XRD to analyze. The samples D2, E2, F2, G2, H2, and I1 calcined at $450^{\circ} \mathrm{C}$ for 30 min, SEM, as shown in Figure 1. It can be seen from the SEM images from (a) to (c), as the first step in the growth of the hydrothermal time, after the second step of the electrochemical preparation of $\mathrm{ZnO}$ gradually reunite and ultimately the formation of flakes of $\mathrm{ZnO}$ films are obtained. With the continued growth of the hydrothermal time, flake structure of $\mathrm{ZnO}$ begins to become thicker and larger, as shown in the SEM (d) and (e). (f) is the SEM of only by step electrochemical preparation of sample I2. It can be seen by the SEM, $\mathrm{ZnO}$ structure is also flake, too. Although samples prepared both by using electrodeposition combination with hydrothermal method and only by step electrochemical method are all porous flakes, two-step prepared sample porousity were higher than that in the sample prepared by one-step. Soaked in the dye will be absorbed more dyes, so it can improve the DSSC short circuit current density, thereby enhancing the performance of the DSSC.

Typical TEM, HRTEM image and SAED of the sample are shown in Figures $1(\mathrm{~g})$ and $1(\mathrm{~h})$.

The XRD pattern of sample F1, F2, I1 in Figure 2. Because the sample F1 growth time is too short, only $2 \mathrm{~h}$, so few $\mathrm{ZnO}$ products are obtained. It can be seen from the XRD 


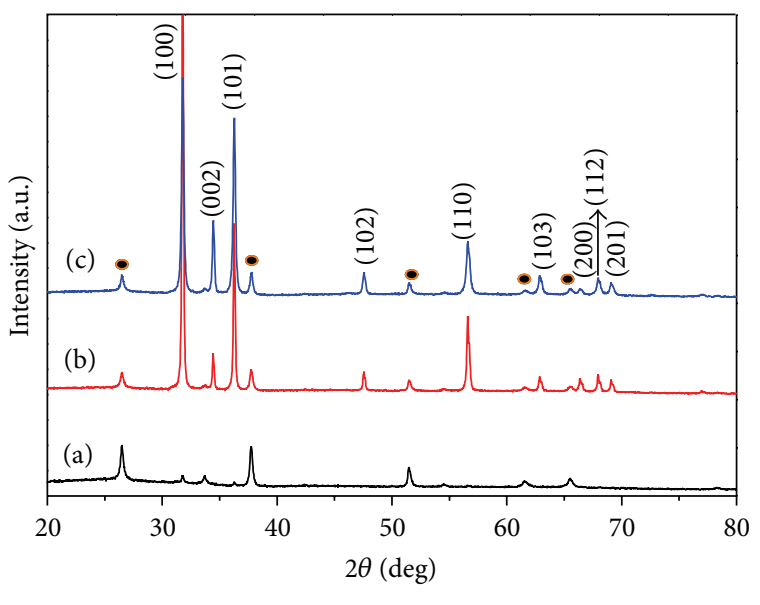

- FTO

FIGURE 2: XRD pattern of the samples F1, F2, and I1, corresponds to the curves (a), (b), and (c), respectively.

patterns that, for one step hydrothermally prepared samples of Fl, peak is less and the intensity of each peak is not high, indicating the crystallization is not very good. But electrodeposition combination with hydrothermal method preparation of the samples F2 and only by step electrochemical method preparation of sample Il the main peak position and peak intensity are almost the same. Compared with Il, F2 is slightly higher than only the peak intensity of (100) direction in the crystal. This is similar to the morphology of the F2 and I1.

\section{Results and Discussion}

The above prepared samples D2, E2, F2, G2, H2, and I1 were immersed into dyes (N719) $12 \mathrm{~h}$, obtaining the $\mathrm{ZnO}$ photoanodes D3, E3, F3, G3, H3, and I2, then with Pt counter electrodes they were assembled into dye-sensitized solar cells (DSSCs) and performance testing, respectively.

Based on samples D3, E3, F3, G3, H3, and I2, $J$ - $V$ curves obtained from DSSCs are presented in Figure 3; Table 1 presents the parameters of DSSCs. Because of only by step hydrothermal method preparation, $\mathrm{ZnO}$ films assembled into DSSCs performance are very low, so they are not listed in this table. It can be seen by the $J-V$ curve, as with increasing in the time of the hydrothermal growth in the first step, the DSSCs short-circuit current density and photoelectric conversion efficiency decreased. The main reason is that with the growth of hydrothermal time, after the second step electrochemical method by the $\mathrm{ZnO}$ surface reunion, flakes of $\mathrm{ZnO}$ gradually formed, resulting in the increase in the surface area, as well as the increase in the load of the dye adsorption. So the short circuit current density and photoelectric conversion efficiency of DSSCs are also increased. But with the growth of the hydrothermal time, flake structure of $\mathrm{ZnO}$ begins to become thicker and larger, the surface area and dyes adsorption decrease, so the short-circuit current density and photoelectric conversion efficiency of DSSC decrease. When the hydrothermal time was $2 \mathrm{~h}$, the performance of

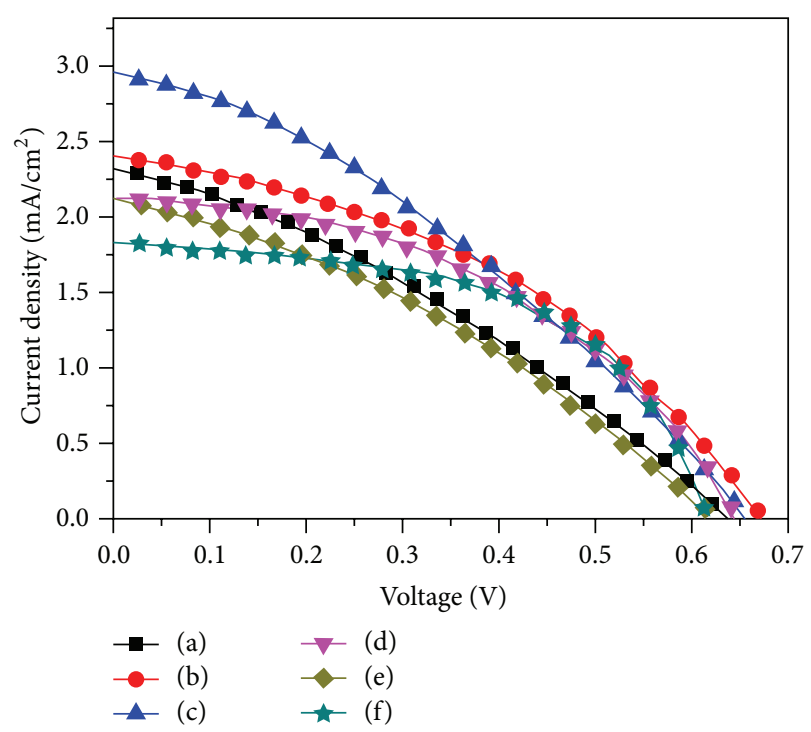

Figure 3: $J-V$ curves obtained from the samples D3, E3, F3, G3, H3, and I2 of DSSC, corresponds to the curves (a), (b), (c), (d), (e), and (f), respectively.

TABLE 1: The performance parameters of DSSC based on samples D3, E3, F3, G3, H3, and I2.

\begin{tabular}{lcccc}
\hline Samples & $V_{\text {oc }}(\mathrm{V})$ & $J_{\text {sc }}\left(\mathrm{mA} / \mathrm{cm}^{2}\right)$ & $\mathrm{FF}$ & $\eta(\%)$ \\
\hline D3 & 0.63 & 2.32 & 0.33 & 0.49 \\
E3 & 0.55 & 2.95 & 0.39 & 0.65 \\
F3 & 0.67 & 2.40 & 0.40 & 0.66 \\
G3 & 0.59 & 2.13 & 0.49 & 0.62 \\
H3 & 0.61 & 2.11 & 0.34 & 0.45 \\
I2 & 0.61 & 1.82 & 0.54 & 0.62 \\
\hline
\end{tabular}

electrodeposition combination with hydrothermal method preparation of samples F3 assembled into DSSC is better than only by step electrochemical method preparation of samples I2 assembly of the DSSC. The main reason is that, compared with only by step electrochemical method, electrodeposition combination with hydrothermal method preparation of $\mathrm{ZnO}$ films have a lot of holes; it is conducive to adsorption of more dyes, resulting in higher short-circuit current density and photoelectric conversion efficiency.

$\mathrm{ZnO}$ photoanodes $\mathrm{I} 2, \mathrm{Fl}^{\prime}$, and $\mathrm{F} 3$ prepared by electrochemical method, hydrothermal method, and electrodeposition combination with hydrothermal method were assembled into DSSC, respectively. Then we do IPCE test and get the test curve shown in Figure 3. It can be seen from IPCE spectra, the wavelength range of photo-electron conversion in the DSSC is between $380-700 \mathrm{~nm}$. The response spectrum by electrodeposition combination with hydrothermal method preparation of samples F3 assembly of DSSC is broader than only by one step method preparation of samples $\mathrm{I} 2$ and $\mathrm{Fl}^{\prime}$ assembly of DSSC. Demonstrate that the capture efficiency based on electrodeposition combination with hydrothermal method preparation of samples F3 assembly of DSSC is higher than the assembly of the DSSC based on only by 


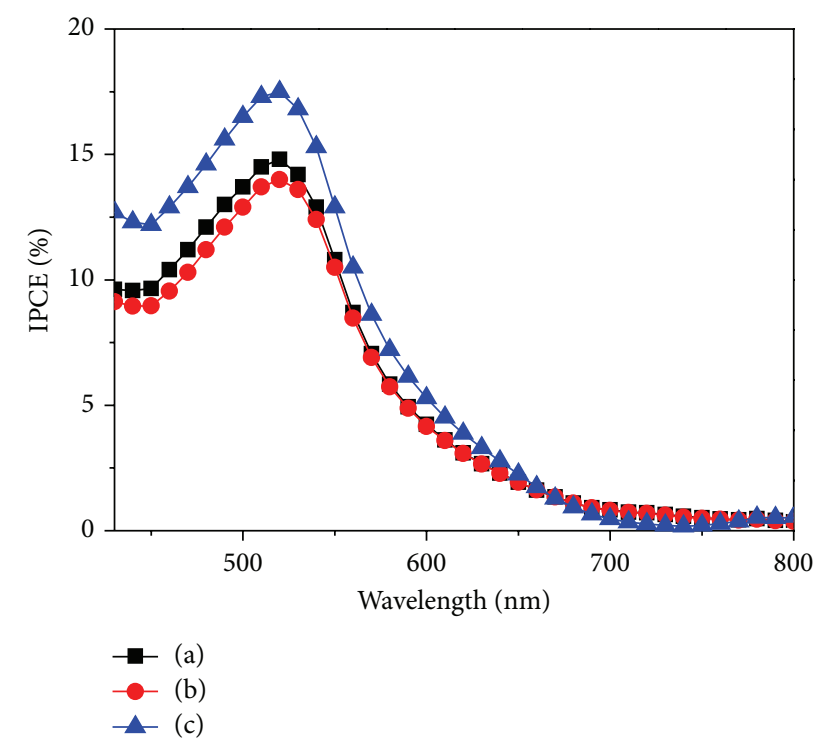

FIGURE 4: The IPCE of samples I2, F1', and F3, corresponds to the curves (a), (b), and (c), respectively.

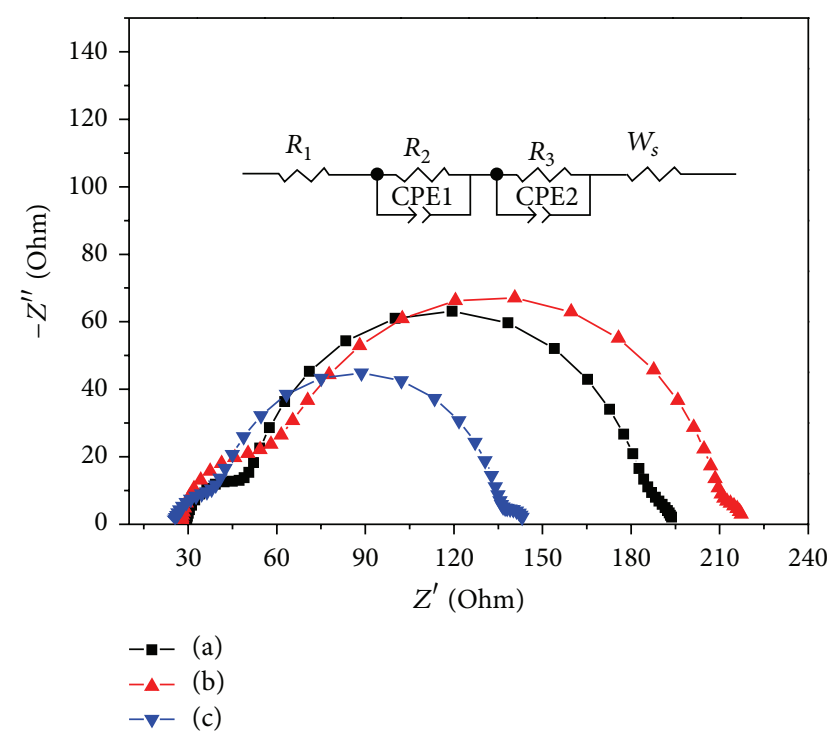

FIgURE 5: The EIS of samples F1', I2, and F3, corresponds to the curves (a), (b), and (c), respectively.

step hydrothermal method and only by step electrochemical preparation of samples. At $520 \mathrm{~nm}$, the photoelectric conversion efficiency of samples $\mathrm{I} 2, \mathrm{Fl}^{\prime}$, and $\mathrm{F} 3$ attains $14.5 \%, 14 \%$, and $17.5 \%$, respectively (Figure 4 ).

Figure 5 shows the alternating current impedance spectra of DSSC based on samples $\mathrm{Fr}^{\dagger}, \mathrm{I} 2$, and $\mathrm{F} 3$, the inset in Figure 5 is the equivalent circuit fitting impedance curve by using the Z-View software. Fitting results are shown in Table 2. As shown in Figure 5, samples $\mathrm{Fl}^{\prime}, \mathrm{I} 2$, and $\mathrm{F} 3$ of the EIS appear three semi-circulars; the semicircle of intermediate frequency corresponds to $\mathrm{ZnO}$ and electrolyte interface electronic composite process, and at the same time corresponds to the $R_{3}$ equivalent circuit. The low
TABLE 2: The fitting results of DSSC electrochemical impedance spectroscopy based on samples $\mathrm{F}^{\prime}$, I2, and F3.

\begin{tabular}{lcccc}
\hline Samples & $R_{1}(\Omega)$ & $R_{3}(\Omega)$ & $\mathrm{CPE} 2(\mu \mathrm{F})$ & $W_{s}(\Omega)$ \\
\hline $\mathrm{F}^{\prime}$ & 29.25 & 130.6 & 38.56 & 14.41 \\
$\mathrm{I} 2$ & 27.16 & 120.8 & 57.42 & 5.67 \\
$\mathrm{~F} 3$ & 25.22 & 94.22 & 41.13 & 9.28 \\
\hline
\end{tabular}

frequency semicircle corresponds to the electrolyte diffusion impedance, the equivalent circuit of the $W_{s}$. CPE2 represents $\mathrm{ZnO}$ and electrolyte electric double layer of capacitance. It can be seen from the fitting data in Table 2, compared to DSSC assembled with the sample F1 only by one step of hydrothermal method, DSSC assembled with the sample I2 only by one step of electrochemical method has the smaller electronic composite impedance $\left(R_{3}\right)$, demonstrating that the electron recombination rate of anode of the sample I2 is relatively low and has longer electron lifetime, while CPE2 is larger. Meanwhile, the Warburg impedance $\left(W_{s}\right)$ of the electrolyte is smaller, so the electrochemical method preparation of $\mathrm{ZnO}$ structure is more conducive to the electrolyte ion diffusion. Compared with one-step preparation of samples $\mathrm{Fl}^{\prime}$ and $\mathrm{I} 2$, electrodeposition combination with hydrothermal method preparation of the sample F3 assembled into DSSC, the external circuit impedance $R_{1}$ minimum. Warburg impedance of the electrolyte $W_{s}$ is slightly larger than only by step electrochemical method preparation of sample I2, but smaller than only by step hydrothermal method preparation of sample $\mathrm{Fl}^{\prime}, \mathrm{CPE} 2$ is less than I2, but greater than $\mathrm{Fl}^{\prime}$. In the three types of DSSC, the $\mathrm{Fl}^{\prime}$ electronic complex impedance $R_{3}$ is maximum, demonstrating the $\mathrm{Fl}^{\prime}$ light electrons on the anode composite probability minimum. On the whole, electrodeposition combination with hydrothermal method preparation of the samples was assembled into DSSC, its performance is superior to only one step method preparation of samples assembled into DSSC. In only one step method preparation of samples, the DSSC performance of electrochemical method preparation is better than the hydrothermal method preparation; it is consistent with the IPCE test results of the previous.

\section{Conclusions}

We have demonstrated an efficient method for preparation of high performance $\mathrm{ZnO}$ photoanodes. After all steps, the $\mathrm{ZnO}$ films formed flack finally. The holes of sample prepared by the electrodeposition combination with hydrothermal method are more than one-step preparation method. It is conducive to absorb more dye; the DSSC short circuit current density is greater than before, thereby enhancing the performance of the DSSC. With the increase of hydrothermal time, the change of $\mathrm{ZnO}$ films surface can offer large surface area to absorb much more dyes. Our results clearly demonstrate that $\mathrm{ZnO}$ photoanodes prepared by electrodeposition combination with hydrothermal method have more functions and show a high performance in solar cells. In addition, we expected to, through deep research, obtain higher conversion efficiency of DSSCs by this method. 


\section{Conflict of Interests}

The authors declare that there is no conflict of interests regarding the publication of this paper.

\section{Acknowledgments}

This work was partially supported by Key Project of Beijing Natural Science Foundation (3131001), Key Project of Natural Science Foundation of China (91233201 and 61376057), Key Project of Beijing Education Committee Science \& Technology Plan (KZ201211232040), State 863 Plan of MOST of PR China (2011AA050527), Beijing National Laboratory for Molecular Sciences (BNLMS2012-21), State Key Laboratory of Solid State Microstructures of Nanjing University (M27019), State Key Laboratory for Integrated Optoelectronics of Institute of Semiconductors of CAS (IOSKL2012KF11), State Key Laboratory for New Ceramic and Fine Processing of Tsinghua University (KF1210), Key Laboratory for Renewable Energy and Gas Hydrate of Chinese Academy of Sciences (y207ka1001), Beijing Key Laboratory for Sensors of BISTU (KF20131077208), and Beijing Key Laboratory for photoelectrical measurement of BISTU (GDKF2013005).

\section{References}

[1] B. O’Regan and M. Grätzel, "A low-cost, high-efficiency solar cell based on dye-sensitized colloidal $\mathrm{TiO}_{2}$ films," Nature, vol. 353, article 737, 1991.

[2] M. Grätzel, "Photoelectrochemical cells," Nature, vol. 414, pp. 338-344, 2001.

[3] A. Hagfeldt, G. Boschloo, L. Sun, L. Kloo, and H. Pettersson, "Dye-sensitized solar cells," Chemical Reviews, vol. 110, no. 11, pp. 6595-6663, 2010.

[4] M. Pagliaro, R. Ciriminna, and G. Palmisano, "Flexible solar cells," ChemSusChem, vol. 1, no. 11, pp. 880-891, 2008.

[5] M. R. Lee, R. D. Eckert, K. Forberich, G. Dennler, C. J. Brabec, and R. A. Gaudiana, "Solar power wires based on organic photovoltaic materials," Science, vol. 324, no. 5924, pp. 232-235, 2009.

[6] B. O'Connor, K. P. Pipe, and M. Shtein, "Fiber based organic photovoltaic devices," Applied Physics Letters, vol. 92, Article ID 193306, 2008.

[7] M. S. Akhtar, M. A. Khan, M. S. Jeon, and O.-B. Yang, "Controlled synthesis of various $\mathrm{ZnO}$ nanostructured materials by capping agents-assisted hydrothermal method for dyesensitized solar cells," Electrochimica Acta, vol. 53, no. 27, pp. 7869-7874, 2008.

[8] H. Chen, L. Zhu, H. Liu, and W. Li, "Growth of $\mathrm{ZnO}$ nanowires on fibers for one-dimensional flexible quantum dot-sensitized solar cells," Nanotechnology, vol. 23, no. 7, Article ID 075402, 2012.

[9] H. Chen, W. Li, Q. Hou, H. Liu, and L. Zhu, "Growth of threedimensional $\mathrm{ZnO}$ nanorods by electrochemical method for quantum dots-sensitized solar cells," Electrochimica Acta, vol. 56, no. 24, pp. 8358-8364, 2011.

[10] P. V. Kamat, "Quantum dot solar cells. Semiconductor nanocrystals as light harvesters," Journal of Physical Chemistry C, vol. 112, no. 48, pp. 18737-18753, 2008.
[11] S. Rühle, M. Shalom, and A. Zaban, "Quantum-dot-sensitized solar cells," ChemPhysChem, vol. 11, no. 11, pp. 2290-2304, 2010.

[12] I. Mora-Seró, S. Giménez, F. Fabregat-Santiago et al., "Recombination in quantum dot sensitized solar cells," Accounts of Chemical Research, vol. 42, no. 11, pp. 1848-1857, 2009. 

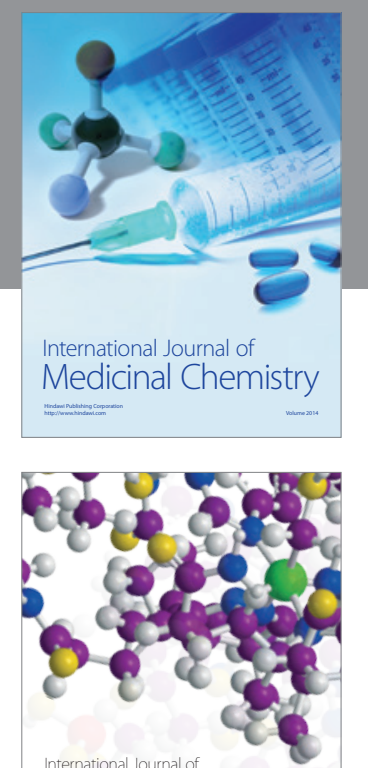

\section{Carbohydrate} Chemistry

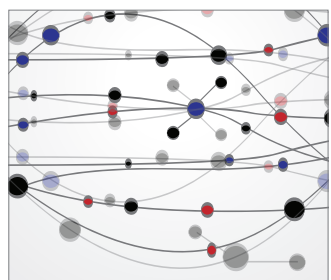

The Scientific World Journal
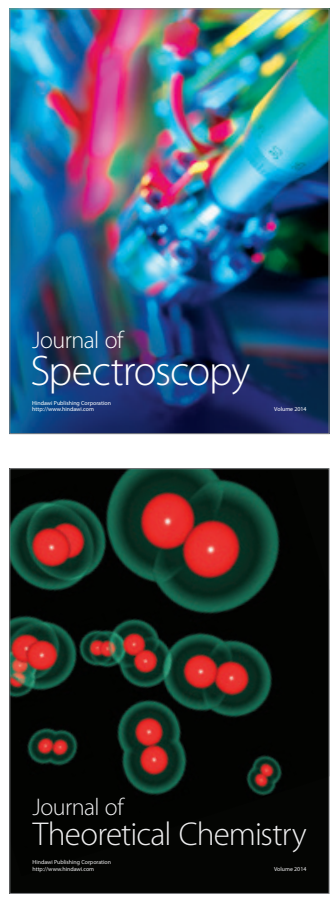
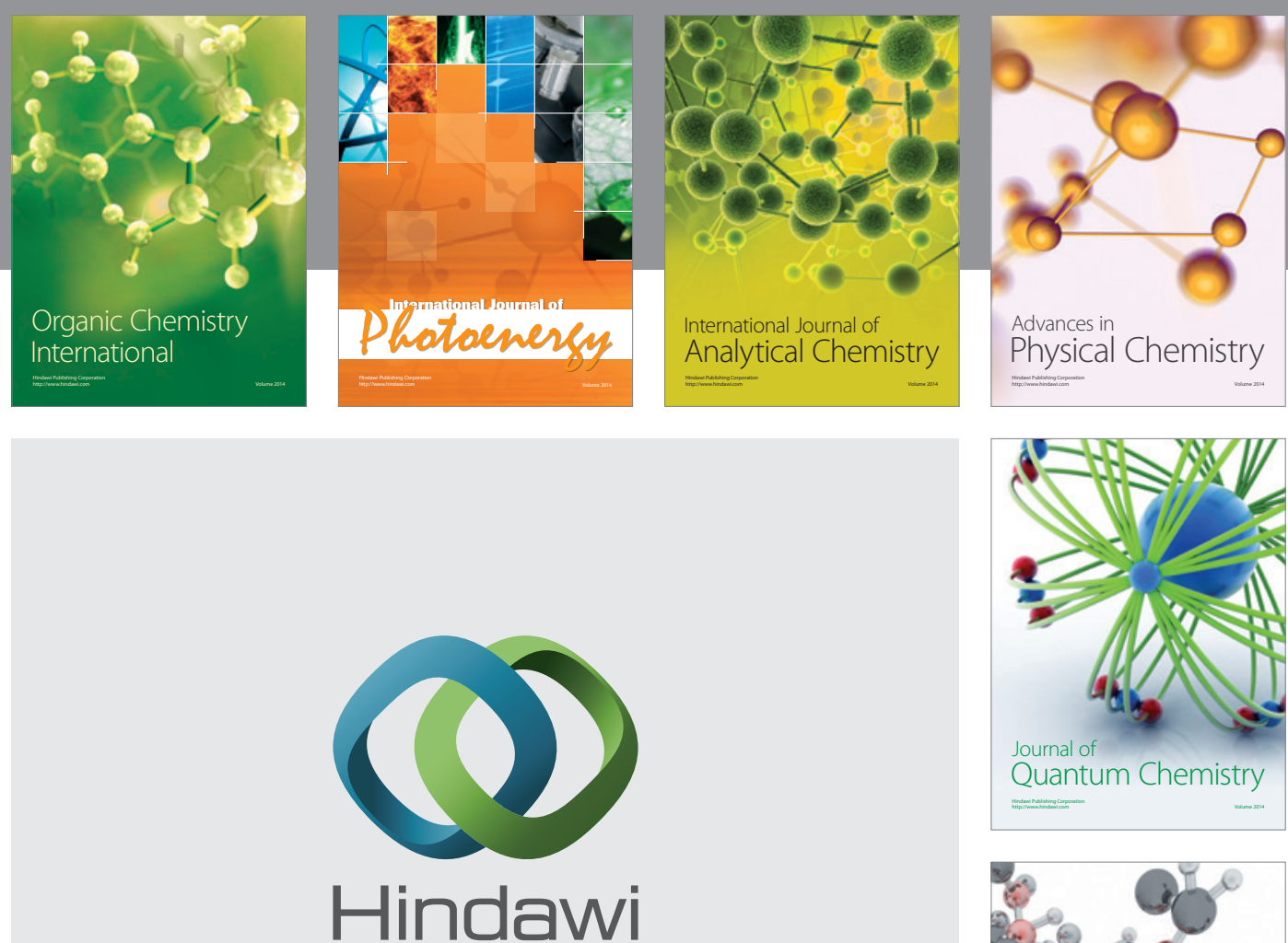

Submit your manuscripts at

http://www.hindawi.com

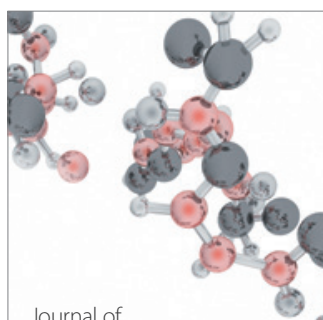

Analytical Methods

in Chemistry

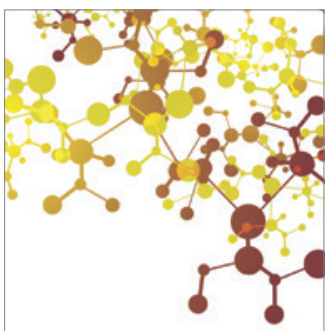

Journal of

Applied Chemistry

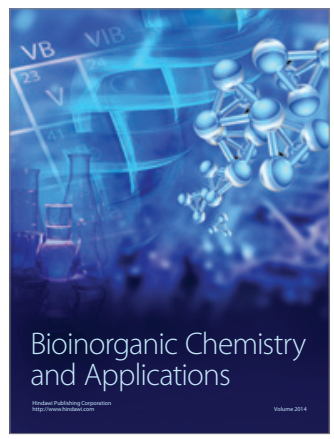

Inorganic Chemistry
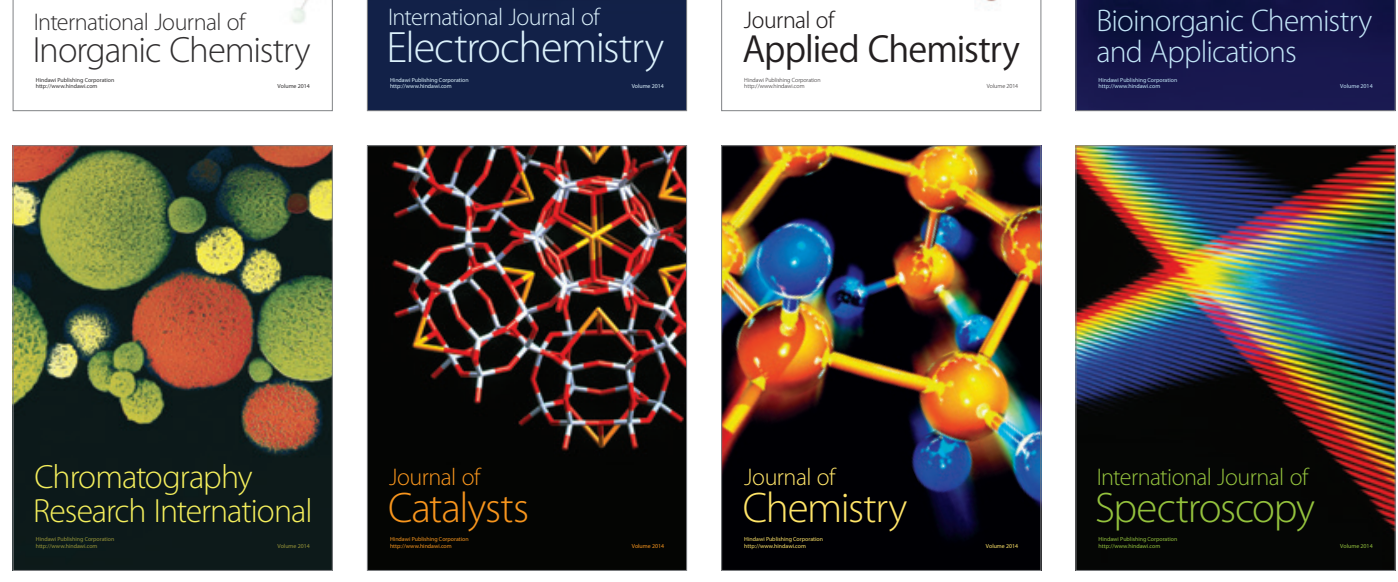